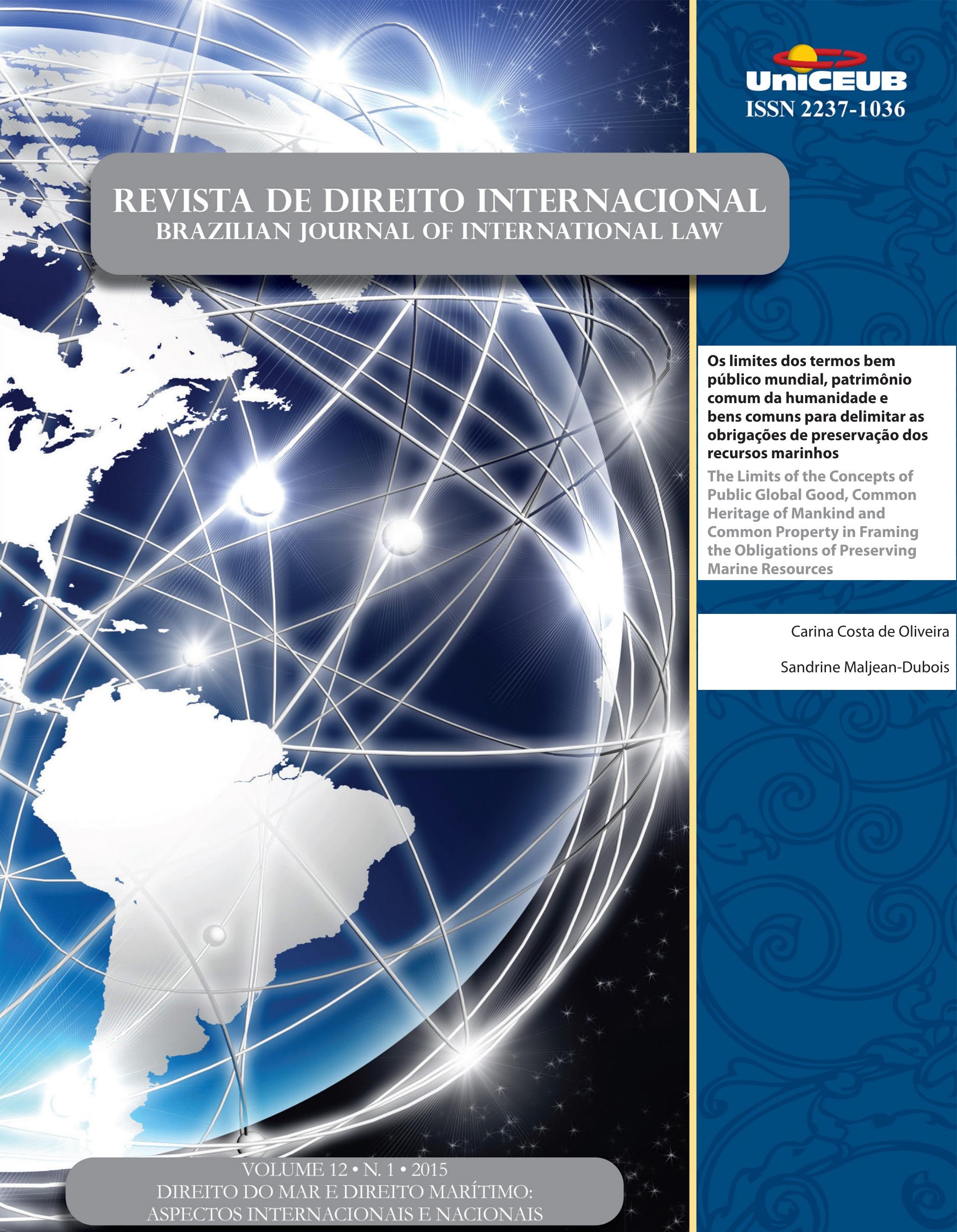




\section{Sumário}

\section{Crônicas}

CRôNICAS DA ATUALIDADE do DiREITO INTERNACIONAL ........................................................ 2

Nitish Monebhurrun (org.)

Towards a european regulation of the importation of conflict minerals?..... 2

Nitish Monebhurrun

Keeping up with the terrorists: the EU's proposed Passenger Name Records (PNR) Directive \& european security

Eshan Dauhoo

A histórica reaproximação de Cuba e EUA

Erika Braga

A contextualização da atual reivindicação da Grécia para receber indenizações por atos da Alemanha durante a Segunda Guerra Mundial . .10

Natália da Silva Gonçalves

José Eduardo Paiva Miranda de Siqueira

Crônicas da jurisprudência do Direito Internacional (CIJ/ITLOS): Decisões da Corte Internacional de Justiça e do Tribunal Internacional Sobre o Direito do Mar .14

Nitish Monebhurrun (Org.)

Corte Internacional de Justiça

Estudo da decisão da Corte Internacional de Justiça no caso Croácia v. Servia (03/02/2015) .14

Liziane Paixão Silva Oliveira e Maria Edelvacy Marinho

Questões relacionadas com a apreensão e detenção de certos documentos e dados: (Timor Leste c. Austrália) - O reconhecimento do retorno de uma relação amigável entre Timor-Leste e Austrália e a nova decisão da CIJ, 6 de maio de 2015 . 20

Gleisse Ribeiro Alves

Tribunal Internacional sobre Direito do Mar

Caso da delimitação da fronteira marítima entre o Gana e a Costa do Marfim no Oceano Atlântico: medidas cautelares $(25 / 04 / 2015)$

Nitish Monebhurrun

Comentário à Opinião Consultiva 21 do Tribunal Internacional para o Direito Do Mar [02/04/2015] (Responsabilidade do Estado de Bandeira pela pesca ilícita, não declarada ou não regulamentada) ...............25

Carina Costa de Oliveira 
CRÔNICAS DO DIREITO INTERNACIONAL DOS INVESTIMENTOS

Nitish Monebhurrun (Org.)

A inclusão da responsabilidade social das empresas nos novos Acordos de Cooperação e de Facilitação dos Investimentos do Brasil: uma revolução 33

Nitish Monebhurrun

\section{O Direito do Mar Perante as JuRisdições INTERnacionais}

CoAstal States' Rights IN THE MARITIME AREAS UNDER UNCLOS .40 Tullio Treves

TACKling illegal, unregulated And unReported Fishing: THE ITLOS Advisory OpINION on Flag State Responsibility for IUU fishing AND THE PRINCiple of DUE DiligenCE ...50 Victor Alencar Mayer Feitosa Ventura

REFLEXões PROVENIENTES do DisSENSO: UMA ANÁLISE CRÍtica A RESPEITO do CASO Austrália versus Japão Perante a Corte InTERnacional de JustiçA .......................................68 Luciana Ferna ndes Coelho

Os TRATADOS INTERNACIONAIS DE DIREITO DO MAR E SEUS EFEITOS SOBRE TERCEIROS ESTADOS ..... 86 Tiago V. Zanella

\section{InStRumentos JURÍdicos PARA A GeStÃo do MAR}

OS LIMITES DOS TERMOS BEM PÚBLICO MUNDIAL, PATRIMÔNIO COMUM DA HUMANIDADE E BENS COMUNS PARA DELIMITAR AS OBRIGAÇÕES DE PRESERVAÇÃO DOS RECURSOS MARINHOS 109 Carina Costa de Oliveira e Sandrine Maljean-Dubois

Os limites do PLANEJAMENTO DA OCUPAÇÃo SUSTENTÁVEL DA ZONA COSTEIRA BRASILEIRA ... 126 Carina Costa de Oliveira e Luciana Coelho

CORRENDO PARA O MAR NO ANTROPOCENO: A COMPLEXIDADE DA GOVERNANÇA DOS OCEANOS E A ESTRATÉGIA BRASILEIRA DE GESTÃO DOS RECURSOS MARINHOS 
A comissão de limites da Plataforma continental (CLPC) E Os DESAFios Na delineaÇÃo DAS PLATAFORMAS CONTINENTAIS ESTENDIDAS................................................... 170

Alexandre Pereira da Silva

\section{A PROTEÇÃo DO MEIO AMBIENTE MARINHO}

O gRANDE JOGo do ÁrTiCo: REFLEXões COM BASE NA PERSPECTIVA DE EXPLORAÇão ECONÔMICA

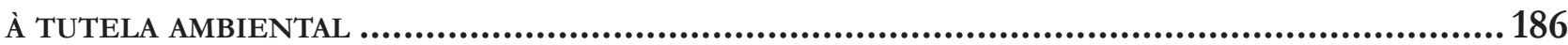

Fernando Rei e Valeria Cristina Farias

Instrumentos Públicos e Privados para a reparação do dano ambiental causado por DERRAMAMENTO DE ÓLEO NO MAR SEM ORIGEM DEFINIDA: AS MANCHAS ÓRFÃS

Renata Brockelt Giacomitti e Katya R. Isaguirre-Torres

O DIREITO INTERNACIONAL PRIVADO E A RESPONSABILIDADE CIVIL EXTRACONTRATUAL POR DANOS AMBIENTAIS CAUSADOS POR TRANSPORTES MARÍTIMOS À LUZ DO DIREITO BRASILEIRO ....... 217 Inez Lopes

A NECESSIDADE DE REPENSAR OS MECANISMOS DE RESPONSABILIDADE AMBIENTAL EM CASO DE riscos de VAZamento de PETRóleo Na Zona Econômica Exclusiva do BrasiL

Marcelo D. Varella

\section{Problemáticas do Direito Marítimo}

A FisCALIZAÇão SANitÁRIA DAS EMBARCAÇÕES EM ÁGUAS JURISDICIONAIS BRASILEIRAS: NOTAS aCERCA da (IN)efetividade da Súmula 50 da AGU

Joedson de Souza Delgado e Ana Paula Henriques da Silva

A IMO E A REPRESSÃo AO ROUBO ARMADO CONTRA NAVIOS: DA RETÓRICA INTERNACIONAL À COOPERAÇÃO REGIONAL

André Panno Beirão e Charles Pacheco Piñon

\section{O Direito do Mar diante da Pirataria}

O DIREITO INTERNACIONAL EM FACE DA PIRATARIA EM ALTO-MAR: UMA PERSPECTIVA CRÍTICA.289 Maiquel Ângelo Dezordi Wermuth e Rafaela Correa 
Pirataria marítima: A EXPERIÊnCIA Somália

Eduardo Augusto S. da C. Schneider

\section{Temas Gerais}

DRAWING THE LINE: ADDRESSING ALLEGATIONS OF UNCLEAN HANDS IN INVESTMENT ARBITRATION*

Mariano de Alba

Para Que Serve a história do Direito internacional?

George Rodrigo Bandeira Galindo

As interferências entre a Política Externa e de Segurança Comum Europeia (Pesc) e O DiREITO DAS NaÇões UNIDAS

Leonardo de Camargo Subtil

Introdução Às regras de aplicaÇão da Convenção da ONU Sobre Contratos de ComPRA E VENDA INTERNACIONAL DE MERCADORIAS E O DIREITO INTERNACIONAL PRIVADO BRASI-

LEIRO 380

Paul Hugo Weberbauer e Eugênia Cristina Nilsen Ribeiro Barza

A REgulaÇÃo das EMPRESAS TRANSNACIONAIS ENTRE AS ORDENS JURÍDICAS ESTATAIS E NÃO ESTATAIS.

Mateus de Oliveira Fornasier e Luciano Vaz Ferreira

OUtLAWING HATE SPEECH IN DEMOCRATIC STATES: THE CASE AGAINST THE INHERENT LimitAtions doctrine concerning Article 10 (1) of the European Convention on Human

Rights 416

Stefan Kirchner 


\title{
Os limites dos termos bem público mundial, patrimônio comum da humanidade e bens comuns para delimitar as obrigações de preservação dos recursos marinhos*
}

\author{
The Limits of the Concepts of Public Global \\ Good, Common Heritage of Mankind \\ and Common Property in Framing the \\ Obligations of Preserving Marine Resources
}

\author{
Carina Costa de Oliveira** \\ Sandrine Maljean-Dubois ${ }^{* * *}$
}

\section{Resumo}

Bem público mundial, patrimônio comum da humanidade e bens comuns são conceitos utilizados para compreender politicamente e legalmente o regime dos recursos marinhos. Contudo, esses conceitos são limitados em sua capacidade de delimitar as obrigações dos Estados e das Organizações Internacionais pela conservação desses recursos. Mesmo que o conteúdo desses termos possa ser questionado, eles direcionam, por meio de suas abstrações, o debate relacionado aos recursos marinhos. A existência desses termos, científicamente ou não, não pode ser ignorada. Para entender a contribuição desses conceitos para os debates jurídicos relacionados à preservação dos recursos marinhos, eles devem estar articulados com obrigações mais precisas tais como a obrigação de cooperar e a obrigação de diligência. Nesse sentido, esse artigo analisa como esses conceitos podem ser combinados com obrigações mais específicas para que tenham aplicação mais convincente e útil no que concerne à preservação dos recursos marinhos.

Palavras-chave: Preservação dos recursos marinhos. Diligência. Cooperação. Obrigações.

* Artigo convidado

** Professora Adjunta da Faculdade de Direito da Universidade de Brasília. Doutora em Direito pela Université Paris II- Panthéon Assas. Coordenadora do Grupo de Estudos em Direito, Recursos Naturais e Sustentabilidade.

*** Diretora de pesquisa no CNRS. Diretora do Centre d'Etudes et de Recherches Internationales et Communautaires (CERIC, UMR 7318 Université Paul Cézanne / CNRS). Professora e pesquisadora em direito internacional e direito europeu ambiental em seu conjunto (criação, implementação e efetividade), tendo dirigido diversas obras coletivas e publicado um grande número de artigos científicos nesse âmbito.

\section{Abstract}

Global public goods, common heritage and global commons are concepts used to understand the legal and the political regime of marine resources. However, these concepts are limited when it comes to determine the obligations of States and International Organizations regarding marine resources conservation. If, for this reason, their intrinsic purpose can be questioned, these concepts nevertheless dominate, in their abstraction, the debate on marine resources. Their existence, whether cientific or not, can therefore not be denied or ignored. To understand what they can concretely offer to the legal discussions on marine resources, they must be articulated with the more precise legal obligations such as the obligation to cooperate 
and the duty of due diligence, as applied to marine resources. Accordingly, this article studies how these concepts can be combined to more concrete obligations so as to have a convincing application.

Keywords: Marine resources preservation. Due diligence. Cooperation. Obligations.

\section{INTRODUÇÃo}

A proliferação de termos vagos e imprecisos dificulta e posterga a delimitação de obrigações relacionadas à preservação do meio ambiente marinho. Conceitos como bem público mundial, bens comuns e patrimônio comum da humanidade estão muitas vezes desconectados de normas capazes de implementá-los. O debate relacionados à tragédia dos comuns ${ }^{1}$ permanece atual, principalmente quando se analisa as estatísticas do aumento da superexploração de recursos marinhos em alto- $\operatorname{mar}^{2}$ e a busca desenfreada pela exploração de recursos em regiões inóspitas como o Ártico e a Antártica $^{3}$. É relevante, portanto, fazer breve apresentação dos conceitos sobre bem público mundial e a relação deste com os recursos marinhos vivos e não vivos, e a delimitação das obrigações internacionais relacionadas à preservação dos recursos marinhos.

1 Ver sobre o tema: OSTROM, E. Governing the commons, the evolution of institutions for collective actions. Cambridge: Cambridge university Press, 1990; HELLER, M. A. The Tragedy of the Anticommons: Property in the Transition from Marx to Markets. Harvard Law Review, 111, p. 622, 1998. p. 622 ets; LOGEAT, C. Les biens privés affectés à l'utilité publique. Paris: L'harmattan, 2011; PARANCE, Béatrice; VICTOR, Jacques de Saint. Repenser les comuns. Paris: CNRS éd., 2014.

2 Ver sobre o tema, por exemplo, as estatísticas elaboradas pela FAO sobre a pesca em alto-mar. Disponível em: < http://www.fao. org/fishery/statistics/en>. Acesso em: 05 maio 2015.

3 Ver sobre o tema as seguintes notícias: Euronews, 13 de maio de 2015. Shell recebe luz verde para a prospeção no Ártico. Disponível em:<http://pt.euronews.com/2015/05/13/shell-recebe-luz-verdepara-a-prospecao-no-artico/>. Acesso em: 10 maio 2015 ; The New York Times, 12 de maio de 2015.Aumentando barreiras em Seattle para repelir gigante petrolífero. Disponível em: $<$ http://www. nytimes.com/2015/05/12/us/grabbing-paddles-in-seattle-to-wardoff-an-oil-giant.html?_r=5>. Acesso em: 20 maio 2015. Para análise de estatísticas na Antártica ver: <https://www.ccamlr.org/en/document/publications/ccamlr-statistical-bulletin-vol-25>. Acesso em: 15 jun. 2015. Ver ainda: REID, Keith. Conserving Antarctica from the Bottom Up: Implementing UN General Assembly Resolution 61/105 in the Commission for the Conservation of Antarctic Marine Living Resources (CCAMLR). In: Ocean Y.B., n. 25 (131), 2011; ROSSI, Christopher R. A particular kind of the grotian tendency and the global commons in a time of high arctic change. In: Int'l $\mathrm{L}$ \& Int'l Rel, n. 11 (1), 2015.
De modo geral, a terminologia bens públicos mundiais não é clara e muito menos precisa. $\mathrm{O}$ termo tem sido utilizado e citado em textos jurídicos em áreas como saúde ${ }^{4}$, meio ambiente ${ }^{5}$, comércio $^{6}$, informação e, por ter sido utilizado reiteradamente, justifica-se a análise da função e do conteúdo deste. O conceito tem como origem os trabalhos de alguns economistas ${ }^{8}$. As organizações internacionais contribuíram, consideravelmente, com o debate sobre o termo desde a publicação do Programa das Nações Unidas para o Desenvolvimento (PNUD) em 1999 intitulada Les biens publics à l'échelle mondiale: la coopération internationale an XXIème siècle $e^{9}$ Esse relatório foi seguido por outros documentos do PNUD ${ }^{10}$ e por documentos realizados por outras

4 Ver: BOIDIN, Bruno. La santé, bien public mondial ou bien marchand: réflexions à partir des expériences africaines. Villeneuve d'Ascq: Presses Universitaires du Septentrion, 2014; GARTNER, David. Global public goods and global health. Duke J. Comp. \& Int'l L., n. 22 (303), 2011-2012.

5 Ver: MORGERA, Elisa. Bilateralism at the Service of Community Interests? Non-judicial Enforcement of Global Public Goods in the Context of Global Environmental Law. The European Journal of International Law, v. 23, n. 3, p. 748-753, 2012; MEYER, Timothy. Global public goods, governance risk and international energy. Duke J. Comp. \& Int'l L., v. 22, n. 319, 2011-2012; KRISCH, Nico. The decay of consent: international law in an age of global public goods. The American Journal of International Law, v. 108, n. 1, p. 16-21, jan. 2014.

6 STAIGER, R.W. Report on the International Trade Regime for the International Task Force on Global Public Goods. 2006. Disponível em: $<$ http://www.regeringen.se/contentassets/4e 7cc9afcd2444d38d5 b507bb6cf9b49/global-public-goods-international-trade>. Acesso em: 10 jun. 2015; MAVROIDIS, Petros C. Free Lunches? WTO as Public Good, and the WTO's View of Public Goods. The European Journal of International Law, v. 23, n. 3, p. 731-742, 2012; CAFAGGI, Fabrizio. Private regulation and the production of global public goods and private 'bads'. The European Journal of International Law, v. 23, n. 3, p. 695-718, 2012; PETERSMANN, Ernst-Ulrich. International Economic Law, "Public Reason" and Multilevel Governance of Interdependent Public Goods". Journal of International Economic Law, n. 14, p. 23-76, 2011.

7 Ver: DG/99/2/KM, UNESCO, Discurso de Kö̈chiro Matsuura, Diretor geral na ocasião do Sommet mondial des régulateurs sur Internet et les nouveaux services. UNESCO, 30 nov. 1999.

8 Ver os trabalhos de P. Samuelson, nos anos 50. Ver ainda: HEATHCOTE, S. Les biens publics mondiaux et le droit international. Quelques réflexions à propos de la gestion de l'intérêt commun. L'Observateur des Nations Unies, n. 13, p. 143, 2002. Ver o texto do Bodansky que retoma a origem do termo nos textos de David Hume e de Adam Smith: BODANSKY, Daniel. What's in a Concept? Global Public Goods, International Law, and Legitimacy. The European Journal of International Law, v. 23, n. 3, p. 652-654, 2012.

9 Ver sobre o tema: KAUL I.; GRUNBERG, I.; STERN, M. A. International Cooperation in the 21st Century. Oxford: Oxford University Press, 1999.

10 Ver, por exemplo: KAUL, Inge et al. Providing Global Public Goods: Managing Globalization. New York: Oxford University Press, 2003. 
organizações como o Banco Mundial ${ }^{11}$. Outras instituições nacionais também se dedicaram a trabalhar o conteúdo do bem público mundial no âmbito, por exemplo, da ajuda ao desenvolvimento ${ }^{12}$.

Observa-se que o termo tem sido utilizado para tratar de desafios de amplitude mundial, com peculiaridades para cada área temática ${ }^{13}$. Alguns artigos jurídicos abordaram o tema sob as seguintes perspectivas: demonstrar as deficiências institucionais gerais no contexto do direito internacional público para enquadrar os bens públicos mundiais, tais como a centralidade do consenso nas negociações dos sujeitos de direito internacional ${ }^{14}$, a capacidade e os limites de tratados bilaterais em contribuir com a gestão dos bens públicos mundiais ${ }^{15}$ e a necessidade de instrumentos processuais e substancias para a implementação dos objetivos do termo ${ }^{16}$; analisar como o direito internacional pode contribuir com questões de governança e de legitimidade das instituições para organizar a gestão desses bens ${ }^{17}$; conectar os bens públicos mundiais a obrigações erga omnes $^{18}$; avaliar questões específicas como a gestão da

11 BANCO MUNDIAL. Effective Use of Development finance for International Public Goods. Global Development Finance, Washington DC, 2001.

12 Ver por exemplo : AGENCIA FRANCESA DE DESENVOLVIMENTO. Biens publics mondiaux et développement: de nouveaux arbitrages pour l'aide ?. Documento de trabalho n. 3, Paris, sept. 2005.

13 Ver sobre o tema: BODANSKY, Daniel. What's in a Concept? Global Public Goods, International Law, and Legitimacy. The European Journal of International Law, v. 23, n. 3, p. 651-668, 2012.

14 KRISCH, Nico. "The decay of consent: international law in an age of global public goods". The American Journal of International Law, v. 108, n. 1, p. 1-40, jan. 2014.

15 MORGERA, Elisa. "Bilateralism at the Service of Community Interests? Non-judicial Enforcement of Global Public Goods in the Context of Global Environmental Law". The European Journal of International Law, v. 23, n. 3, p. 743-767, 2012.

16 NOLLKAEMPER, André. "International Adjudication of Global Public Goods: The Intersection of Substance and Procedure". The European Journal of International Law, v. 23 n. 3, p. 769- 791, 2012.

17 SHAFFER, Gregory. "International Law and Global Public Goods in a Legal Pluralist World". The European Journal of International Law, v. 23, n. 3, p. 669-693, 2012; BODANSKY, Daniel. "What's in a Concept? Global Public Goods, International Law, and Legitimacy". The European Journal of International Law, v. 23, n. 3, p. 653, 2012. No mesmo sentido: CAFAGGI Fabrizio, CARON, David D. "Global Public Goods amidst a Plurality of Legal Orders: A Symposium". The European Journal of International Law, v. 23, n. 3, p. 645, 2012.

18 BODANSKY, Daniel. "What's in a Concept? Global Public Goods, International Law, and Legitimacy". The European Journal of International Law, v. 23, n. 3, p. 653, 2012. Ver ainda: BENZING, Markus. Community Interests in the Procedure of International produção de energia ${ }^{19}$. Uma perspectiva que merece ser analisada, e que não foi objeto de um estudo atilado, refere-se à articulação de obrigações próprias e precisas ao conteúdo dos bens públicos mundiais, objeto sobre o qual esse artigo pretende se aprofundar no que concerne à gestão dos recursos marinhos.

As características principais dos bens públicos mundiais constituem a não rivalidade e a não exclusividade ${ }^{20}$. Significa dizer que não existe rivalidade entre potenciais utilizadores do bem, pois todos poderiam utilizá-lo sem reduzir a disponibilidade deste para o uso de outros interessados. Contudo, a terminologia bem público mundial parece não ser a mais adequada, pois, nos termos do dicionário Salmon de direito internacional público ${ }^{21}$, o bem é um « elemento móvel ou imóvel suscetível de apropriaçã $\mathrm{O}^{22}$ », o que pode parecer estar em contradição com a noção de bem público mundial. Além disso, público se opõe, normalmente, a privado. Para um jurista, o adjetivo evoca a dominialidade pública, caracterizada pela inaliabilidade desta. Tendo procedência do direito interno, a distinção entre público e privado não pode ser transposta sem modificações ao âmbito internacional. $\mathrm{O}$ adjetivo mundial é, sem dúvida, a parte do tripé que resulta em menos dificuldade. Ele marca a escala global da questão. No entanto, global é muitas vezes apenas uma das perspectivas de ação para um problema. A gestão dos oceanos, por exemplo, é multiescalar, indo do local ao global simultaneamente. Dito de outra forma, mesmo que mundial, um bem público necessita de ação nas esferas local, nacional e internacional.

Pode-se questionar, ainda, de que modo o termo "público" difere-se do termo "comum". Por que falar de bem público ao invés de bem comum, considerando-se que o termo "público" não tem sentido na ordem jurídica internacional enquanto o termo "comum" já está juridicamente consagrado (interesse comum da humanidade, patrimônio comum da humanidade, etc.)? Mas, mesmo que "comum" já esteja juridicamente consagra-

Courts and Tribunals. The Law and Practice of International Courts and Tribunals, n. 5, p. 374, 2006.

19 MEYER, Timothy. Global public goods, governance risk and international energy. Duke J. Comp. \& Int'l L., v. 22, n. 319, 20112012.

20 BODANSKY, Daniel. What's in a Concept? Global Public Goods, International Law, and Legitimacy. The European Journal of International Law, v. 23, n. 3, p. 652, 2012.

21 SALMON, J. (Dir.). Dictionnaire de droit international public. Bruxelles: Bruylant, 2001. p. 126.

22 O texto original tem o seguinte conteúdo: Élément mobilier ou immobilier susceptible d'appropriation. 
do, qual é essa comunidade ${ }^{23}$. Não há comunidade jurídica que represente a comunidade sociológica, mais ou menos existente, que esteja submetida à mesma ordem jurídica ${ }^{24}$.

Segundo o PNUD, o termo público é justificado pelo triângulo de publicness no qual se inscrevem esses bens. Mais precisamente, o bem público mundial é três vezes mundial: público em seu consumo, e o acesso a esse bem é livre e não exclusivo; público no processo de participação, processo político aberto e inclusivo; público na distribuição de privilégios, diante da qual todos podem se beneficiar ${ }^{25}$. Constata-se que, atualmente, raros são os bens públicos mundiais que possam refletir, simultaneamente, essas três características. Esses objetivos só poderão ocorrer no contexto da existência de uma sociedade internacional, sendo esta apenas um projeto e não uma realidade. Em suma, o bem público mundial ainda não exprime regime jurídico peculiar, específico. Trata-se de qualificação não jurídica, apesar das diversas referências em diferentes áreas do direito internacional. Essa constatação não significa que não possam ser atribuídos compromissos e obrigações específicas para a gestão dos chamados bens públicos mundiais. É possível vinculá-los, por exemplo, a terminologias consolidadas no direito internacional que possuem algumas das características dos bens públicos mundiais.

No que tange aos recursos vivos e não vivos marinhos, a terminologia bem público mundial encontra parentesco no âmbito dos recursos marinhos no conceito patrimônio comum da humanidade ${ }^{26}$, com relação aos

23 JOUANNET, E. L'idée de communauté humaine. In: ARCHIVES de philosophie du droit. La mondialisation entre illusion et utopia. t. 47 , p. 191.

24 JOUANNET, E. L'idée de communauté humaine. In: ARCHIVES de philosophie du droit. La mondialisation entre illusion et utopia. t. 47 , p. 191.

25 PNUD. Providing Global Public Goods: Managing Globalization 25 Questions \& Answers. New York: UNDP/ODS, 2002, p. 3-5. Disponível em: <http://web.undp.org/globalpublicgoods/globalization/pdfs/ques-ans.pdf>. Acesso em: 10 maio 2015.

26 Ver sobre o tema: MERCURE, P.F. L'échec des modèles de gestion des ressources naturelles selon les caractéristiques du concept de patrimoine commun de l'humanité. Revue de droit d'Ottawal Ottawa Law Review, v. 28, p. 45, 1996- 1997; TRÉBULLE, F.G. La propriété à l'éprewve du patrimoine commun: le renouveau du domaine universel. Études offertes au professeur Malinvaud, Lexis Nexis. 2007; FRANCKX, Erik. The International Seabed Authority and the Common Heritage of Mankind: The Need for States to Establish the Outer Limits of their Continental Shelf. The International Journal of Marine and Coastal Law, n. 25, p. 543-567, 2010;

LODGE, Michael W. The Common Heritage of Mankind. The International Journal of Marine and Coastal Law, n. 27, p. 733-742, 2012; fundos marinhos; e no termo bens comuns ${ }^{27}$ utilizado para caracterizar recursos sobrejacentes aos fundos marinhos. Diante de um contexto no qual o patrimônio comum da humanidade tem vocação para ser aplicado aos espaços ou aos recursos, não é necessariamente o caso do bem público mundial. No caso deste, a sua utilização não está conectada à internacionalização ou à apropriação de um bem, mas à efetiva cooperação para a efetiva e concreta gestão deste. Por esse ângulo, o termo pode complementar e ampliar o conteúdo dos termos patrimônio comum da humanidade e bem comum para corresponder, mais precisamente, à noção de cooperação para a preservação do recurso ${ }^{28}$. Esse efeito de cooperação pode ser constatado em regimes de res communis, nos chamados bens comuns. Por outro lado, o regime do patrimônio comum da humanidade se diferencia do conceito de bem público mundial em virtude da possibilidade de uso exclusivo dos fundos marinhos em determinadas circunstâncias. Contudo, essa possibilidade de uso exclusivo por meio, por exemplo, de contratos de exploração dos fundos marinhos, não afasta a utilidade da análise de instrumentos que possam implementar a obrigação de cooperação para a gestão dos recursos marinhos no âmbito da apropriação particular ou coletiva ${ }^{29}$.

NOYES, John E. The common heritage of mankind: past, present, and future. Denv. J. Int'l L. \& Pol'y, n. 20, 447, 2011-2012; BASLAR, Kemal. The Concept of the Common Heritage of Mankind in International Law. Hague: Nijhoff Publishers, 1998; SHACKELFORD, Scott J. The Tragedy of the Common Heritage of Mankind. Stan Envtl LJ, n. 28, 2009; JOYNER, C. Legal Implications of the Concept of the Common Heritage of Mankind. Int'l \& Comp. LQ, n. 35, 1986.

27 PARANCE, Béatrice; VICTOR, Jacques de Saint. Repenser les comuns. Paris: CNRS éd. 2014; DEBLOCK, Christian; DELAS, Olivier. Le bien commun comme réponse politique à la mondialisation. Bruxelles: Bruylant, 2003; GORDILLO, José Luis. La Protección de los bienes comunes de la humanidad: un desafío para la política y el derecho del siglo XXI. Madrid: Editorial Trotta , 2006; KU, Charlotte. The Concept of Res Communis in International Law. History of European Ideas, v. 12, n. 4, 1990.

28 A relevância do conceito bem público mundial para a cooperação já foi destacada por alguns autores a exemplo de: BARRETT, Scott. Why Cooperate? The Incentive to Supply Global Public Goods. Oxford: Oxford University Press, 2007; CAFAGGI Fabrizio, CARON, David D. Global Public Goods amidst a Plurality of Legal Orders: A Symposium. The European Journal of International Law, v. 23 , n. 3 , p. 645,2012 . Sobre a conexão entre a preservação do meio ambiente e a necessidade de cooperação ver: MORGERA, Elisa. Bilateralism at the Service of Community Interests? Non-judicial Enforcement of Global Public Goods in the Context of Global Environmental Law. The European Journal of International Law, v. 23, n. 3, p. 748-753, 2012.

29 Sobre o tema do regime da propriedade individual e coletiva no contexto dos bens públicos mundiais ver: CAFAGGI, Fabrizio. 
Em suma, efeito útil da terminologia bem público mundial, no âmbito dos recursos marinhos, consiste em articular os termos já consagrados no direito internacional público para ampliá-los por meio da conexão a obrigações relacionadas à preservação dos recursos. Entre as obrigações específicas consolidadas em direito internacional, podem ser citadas a obrigação de cooperar e a obrigação de due diligence. Outras obrigações poderiam ser citadas, tal como a obrigação de agir em conformidade com o princípio da precaução ${ }^{30}$. No entanto, não se pode afirmar que a obrigação citada já esteja consolidada no direito internacional. Outro critério de seleção das obrigações consistiu no possível impacto nacional e internacional da obrigação, o que é aplicável às duas obrigações mencionadas. Assim, é relevante analisar a configuração da obrigação de cooperação (1) e de due diligence (2) no contexto da preservação dos recursos do meio ambiente marinho, considerando-se que há limites consideráveis para essa operacionalização.

\section{Os LIMITES DA OPERACIONALIZAÇÃO DA OBRIGAÇÃO DE COOPERAR PARA A PRESERVAÇÃO DO MEIO AMBIENTE MARINHO}

O conteúdo de gestão do bem público mundial ainda não contribui com a operacionalização da obrigação de cooperar para a preservação do meio ambiente marinho. Considerando que o termo bem público mundial ainda não é juridicamente operatório, outros termos cuja utilização seja mais consolidada no direito internacional devem ser analisados. Os bens comuns, por exemplo, possuem contorno jurídico mais claro no que concerne ao regime aplicado aos recursos marinhos existentes no alto-mar ${ }^{31}$. Por sua vez, o termo patrimônio comum da

Private regulation and the production of global public goods and private 'bads'. The European Journal of International Law, v. 23, n. 3, p. 703-707, 2012. Ver, especificamente, p. 796.

30 Sobre o tema ver: MALJEAN-DUBOIS, Sandrine. The Role of International Law in the Promotion of the Precautionary Principle. Disponível em: <http://www.iales-aides.com/ uploads/1/3/9/6/13963183/the_role_of_international_law_ in_the_promotion_of_the_precautionary_principle_-_sandrine_ maljean-dubois.pdf $>$. Acesso em: 15 jun. 2015; MARR, Simon. The Southern Bluefin Tuna Cases: The Precautionary Approach and Conservation and Management of Fish Resources. European Journal of International Law, v. 11, n. 04, p. 815-831, 2000.

31 Ver sobre o tema: KAYE, Stuart. Enforcement Cooperation in Combating Illegal and Unauthorized Fishing: An Assessment of Contemporary Practice. Berkeley J. Int'l L., n. 32, 2014, p. 316-329; humanidade possui contornos mais delimitados no que tange à gestão dos fundos marinhos. Antes de analisar o conteúdo de cooperação existente nos dois termos já consolidados no direito internacional, demonstrar-se-á que a obrigação de cooperação para a preservação dos recursos marinhos existe no direito internacional.

O princípio da cooperação consiste em princípio geral do direito internacional público ${ }^{32}$ e do direito internacional ambiental em particular. A ação conjunta dos Estados em razão de um interesse comum pode ser evidenciada em diversos tratados na área ambiental, principalmente nos preâmbulos ${ }^{33}$ nos quais se exige

TELESETSKY, Anastasia. Laundering Fish in the Global Undercurrents: Illegal, Unreported, and Unregulated Fishing and Transnational Organized Crime. Ecology L.Q., n. 41, p. 939-998, 2014; MELLO, Celso D. De Albuquerque. Alto-mar. Rio de Janeiro: Renovar, 2001. O termo bens comuns será utilizado no contexto do regime de res communis.

32 Ver: Carta das Nações Unidas, art. 1², inciso 3; artigo 11. 1; artigo 13. 1. a), b); Declaração 2625(XXV) relativa aos princípios do direito internacional relacionados às relações amigáveis e à cooperação entre os Estados.

33 Convenção das Nações Unidas sobre a luta contra a desertificação nos países gravemente atingidos pela seca ou pela desertificação em particular na África: "Reconnaissant que la désertification et la sécheresse constituent un problème de dimension mondiale puisqu'elles touchent toutes les régions du monde, et qu'une action commune de la communauté internationale s'impose pour lutter contre la désertification et/ou atténuer les effets de la sécheresse"; Convenção internacional sobre a regulamentação da caça à baleia (2 de dezembro de 1946) " [...] les nations du monde ont intérêt à sauvegarder, au profit des générations futures, les grandes ressources naturelles représentées par l'espèce baleinière »; Convenção Africana sobre a Conservação da Natureza e dos Recursos Naturais (Convenção da Argéria, 1968), "Desireux d'entreprendre une action individuelle et collective en vue de la conservation, de l'utilisation et du développement de ce capital par l'établissement et le maintien de son utilisation rationnelle pour le bien-être présent et futur de l'humanité", "Affirmant que la conservation de l'environnement mondial est une préoccupation commune à l'humanité tout entière" (Convenção de Maputo, 2003); Convenção sobre o comércio internacional de espécies de fauna e de fauna selvagens ameaçadas de extinção (Washington, 3 de março de 1973), "Reconnaissant que la faune et la flore sauvages constituent de par leur beauté et leur variété un élément irremplaçable des systèmes naturels, qui doit être protégé par les générations présentes et futures". O preâmbulo da Convenção sobre a conservação de espécies migratórias que pertençam à fauna selvagem dispõe que: “[...] Reconnaissant que la faune sauvage, dans ses formes innombrables, constitue un élément irremplaçable des systèmes naturels de la terre, qui doit être conservé pour le bien de l'humanité; Conscientes de ce que chaque génération humaine détient les ressources de la terre pour les générations futures et a la mission de faire en sorte que ce legs soit préservé et que, lorsqu'il en est fait usage, cet usage soit fait avec prudence; Convenção-quadro das Nações Unidas sobre Mudanças Climáticas (1992), "Conscientes que les changements du climat de la planète et leurs effets néfastes sont un sujet de préoccupation pour l'humanité tout entière"; "Conscientes que le caractère planétaire des changements 
a cooperação entre os sujeitos de direito internacional. Exemplos de cooperação podem ser observados em resultados do Protoloco de Montreal sobre a Camada de Ozônio ${ }^{34}$ e sobre o Protocolo de Kyoto na área do clima por meio de instrumentos sofisticados como mecanismos financeiros. Em outras áreas, também existem mecanismos financeiros originais que permitem fornecer uma base financeira para a cooperação internacional tal como uma porcentagem das passagens de avião com o objetivo de contribuir para a compra de medicamentos (UNITAID) $^{35}$, ou de vacinas ${ }^{36}$. Porém, mesmo que

climatiques requiert de tous les pays qu'ils coopèrent le plus possible et participent à une action internationale, efficace et appropriée, selon leurs responsabilités communes mais différenciées, leurs capacités respectives et leur situation sociale et économique" (preâmbulo); "Il incombe aux Parties de préserver le système climatique dans l'intérêt des générations présentes et futures, sur la base de l'équité et en fonction de leurs responsabilités communes mais différenciées et de leurs capacités respectives. Il appartient, en conséquence, aux pays développés parties d'être à l'avant-garde de la lutte contre les changements climatiques et leurs effets néfastes" (artigo 3, \$1). A obrigação de cooperação no campo do meio ambiente é enunciada de um modo geral na Declaração do Rio sobre o meio ambiente e o desenvolvimento: «Os Estados devem cooperar com um espírito de parceria mundial em via de conservar, de proteger e de restabelecer a saúde e a integridade do ecossistema terrestre" (princípio 7). A Declaração destaca a aplicação do princípio no âmbito científico e técnico (princípio 9), no domínio comercial (princípio 12), ou ainda no que tange à notificação aos Estados das catástrofes naturais e a outras situações de urgência da mesma ordem suscetíveis de efeitos transfronteiriços (principe 18), ou ainda a informação e a consulta aos Estados suscetíveis de serem afetados pelas atividades que podem ter efeitos transfronteiriços sobre o meio ambiente (princípio 19). A Declaração termina pelo princípio 27 segundo o qual "Os Estados e os povos irão cooperar de boa-fé e imbuídos de um espírito de parceria para a realização dos princípios consubstanciados nesta Declaração, e para o desenvolvimento progressivo do direito internacional no campo do desenvolvimento sustentável”.

34 SCHEMEIL, Y. Des types purs de ressources mondiales communes non marchandes? AFSP / Section d'Etudes Internationales - Colloque Les biens publics mondiaux. Pau, 2001. p. 4. Essas análises poderão ser relativizadas no futuro. Ver: "Summary of the Fourteenth Meeting of the Parties to the Montréal Protocol and the Sixth Conference of the Parties to the Vienna Convention, 25-29 novembro 2002". Earth Negociations Bulletin, v. 19, n. 24, p. 16. Ver, ainda, a análise de THEYS, J.; FAUCHEUX, S.; NOËL, J.F. La guerre de l'ozone. Futuribles, n. 125, p. 51-66, out. 1988; FAUCHEUX S.; NOËL, J. F. Les menaces globales sur l'environnement, Paris: Repères La Découverte, 1990. 35 A contribuição sobre os bilhetes de avião destinados a financiar o acesso dos países mais pobres aos medicamentos contra a malária, a tuberculose e a AIDs por meio de uma facilidade internacional de compras de medicamentos (UNITAID) conta hoje com a contribuição de mais de 27 Estados. UNITAID reune os fundos necessários para comprar os medicamentos, centraliza os pedidos diante de um grupo grande de compradores. Pode, portanto, fazer pedidos em grande quantidades e obter os melhores preços. Sobre o tema ver: <http://www.unitaid.eu/>. Acesso em: 15 jun. 2015. 36 IFFIM (International Finance Facility for Immunisation - Facilidade internacional para a vacinação) tem mobilizado milhões de existam compromissos vinculantes ou não vinculantes, a efetividade desses instrumentos ainda é questionável.

A obrigação de cooperação em matéria ambiental também está presente no direito do mar. Por exemplo, a Convenção de Montego Bay prevê no artigo 192 uma obrigação geral de que "Os Estados possuem a obrigação de proteger e de preservar o meio marinho". Os costumes também são fonte de reconhecimento da obrigação, o que pode ser constatado em alguns julgados relacionados ao tema do mar: "[...] obrigação de cooperar constitui, em virtude da parte XII da Convenção de Montego Bay e do direito internacional geral, um princípio fundamental em matéria de prevenção da poluição do meio marinho do qual decorrem direitos que podem ser garantidos pelo Tribunal [...]"37.

No âmbito da Corte Internacional de Justiça (CIJ), pode ser citada a decisão de 2010 no Caso Papeleiras que afirmou a existência de uma obrigação geral de cooperação em matéria de meio ambiente, no seguintes termos: "[...] obrigação de realizar uma avaliação do impacto ambiental quando a atividade puder causar um risco prejudicial importante em um contexto transfronteiriço, em particular diante de um recurso compartilhado" 38 . Assim, um dos instrumentos de cooperação relacionados à proteção ambiental, destacado pela Corte, consistiu na avaliação de impacto ambiental. Ainda sobre a avaliação, a Corte afirmou que trata-se de "[...] prática aceita amplamente pelos Estados nos últimos anos", e, ainda, uma "obrigação de diligência e um dever de prevenção" sem indicar, no entanto, se essa cooperação é uma obrigação costumeira ou convencional ${ }^{39}$. Com base nessa decisão, verifica-se que a avaliação de impacto ambiental não cumpre apenas o papel de autorização do projeto. A Corte afirma que uma vez que as operações tenham começado, uma fiscalização contínua dos efeitos do projeto ao meio ambiente deve ser monitorada durante todo o projeto ${ }^{40}$.

dólares anualmente para lidar com o tema. Ver os relatórios de mobilização financeira em: <http://www.iffim.org/finance/trusteesreports-and-financial-statements/>. Acesso em: 20 jun. 2015.

37 TRIBUNAL INTERNACIONAL DO DIREITO DO MAR. Iranda c. Reino Unido, The Mox Plant Case, decisão das medidas provisórias no dia 3 de dezembro de 2001, parágrafo 82.

38 "[...] obligation de procéder à une évaluation de l'impact sur l'environnement lorsque l'activité industrielle projetée risque d'avoir un impact préjudiciable important dans un cadre transfrontière, et en particulier sur une ressource partagée".

39 Artigo 41.

40 TRIBUNAL INTERNACIONAL DO DIREITO DO MAR. Iranda c. Reino Unido, The Mox Plant Case, decisão das medidas 
Perante esse cenário, serão analisados os limites da preservação do meio ambiente marinho por meio do regime de res communis(a) e do patrimônio comum da humanidade (b) para a implementação da obrigação de cooperação, a fim de preservar os recursos marinhos.

Os limites do regime de res communis

O regime jurídico res communis pode não contribuir com a implementação da cooperação dos sujeitos de direito internacional para a preservação dos recursos marinhos. A superexploração dos recursos, avaliada por meio de relatórios e de julgados, no âmbito da $\mathrm{FAO}^{41}$, da $\mathrm{CIJ}^{42}$, entre outras organizações, evidencia a falta de instrumentos substanciais e processuais que operacionalizem a cooperação. O principal recurso marinho que pode ser utilizado como objeto de análise desse regime é o recurso pesqueiro. Portanto, a pesca será central na análise da implementação do regime de res communis para a preservação do meio ambiente marinho. Considerando que o conteúdo do bem público mundial é a cooperação, é pertinente relacioná-lo ao regime de res communis, bem como demonstrar os limites do termo bem comum para a implementação da obrigação de cooperação dos Estados para a gestão dos recursos marinhos que estiverem em áreas sob a jurisdição dos Estados ou em áreas que estiverem além das jurisdições nacionais.

A Tragedy of commons de Hardin de $1968^{43}$ descreve o abuso no uso dos bens comuns: em razão de os bens serem comuns, o seu acesso é livre e não regulado, o que resulta potencialmente em sua superexploração. Se a "desafetação patrimonial permite [...] a liberdade de uti-

provisórias no dia 3 de dezembro de 2001, parágrafo 205.

41 Ver sobre o tema, por exemplo, as estatísticas elaboradas pela FAO sobre a pesca em alto-mar. Disponível em: < http://www.fao. org/fishery/statistics/en>. Acesso em: 05 maio 2015.

42 Ver um dos últimos casos julgados pela Corte Internacional de Justiça, o caso Austrália c. Japão, caso Baleias, decisão de 31 de março de 2014. Ver: OLIVEIRA, Liziane Paixão Silva; MARINHO, Maria Edelvacy. O caso Austrália c. Japão perante a Corte Internacional de Justiça, Decisão, 31 de março de 2014. In: MONEBHURRUN, Nitish. Decisões da corte internacional de justiça e do tribunal internacional sobre o direito do mar. RDI, Brasília, v. 12, n. 2, p. 4349, 2014. Ver ainda: MALJEAN-DUBOIS, Sandrine; KERBRAT, Yann. La Cour Internationale de Justice face aux enjeux de protection de l'environnement : réflexions critiques sur l'arrêt du 20 avril 2010 , Usines de pâte à papier sur le fleuve Uruguay (Argentine c. Uruguay). RGDIP, n. 1, t. CXV, p. 39-75, 2011. Ver ainda: Caso julgado pelo Tribunal Internacional do Direito do Mar, Southern Bluefin Tuna (New Zealand-Japan, Australia-Japan), Medida provisória, agosto de 1999.

43 HARDIN, Garrett. The Tragedy of the Commons. Science 13, v. 162, p. 1243-1248, dez. 1968. lização" ela não providencia meios " contra os apetites individuais" $"$. Caracterizada pela liberdade de acesso e por uma liberdade ilimitada de exploração, o regime tradicional de res communis não é capaz de limitar, por si só, o risco de degradação e de esgotamento dos recursos ${ }^{45}$.

Prolongando-se o res communis do direito romano, cultivado em seguida pelos juristas teólogos do século XVI (Vitoria, Suarez) e posteriormente sistematizado pela escola de direito natural de Grotius, ele consiste em realizar um esforço para triunfar contra todos por meio de um comportamento autocentrado nas atividades territoriais concorrentes ${ }^{46}$. A melhor ilustração é fornecida pelo alto-mar, destinado à livre utilização de todos, aberto à liberdade de navegação para todas as bandeiras ${ }^{47}$. Trata-se da velha questão doutrinária do século XVII : mare clausum (Selden) contra mar liberum (Grotius). O último triunfou no final. $\mathrm{O}$ artigo $87 \mathrm{da}$ Convenção de Montego Bay dispõe que "O alto-mar está aberto a todos os Estados, que eles sejam costeiros ou sem litoral"; o art. 89 indica que "Nenhum Estado não pode legitimamente pretender submeter qualquer parte do alto-mar à sua soberania".

A tendência natural da sociedade internacional é de afetação, de apropriação: a soberania estatal é "expasionista por sua dinâmica inerente, exclusivista por sua própria lógica ${ }^{48}$. Assim, diversos aspectos em direito do mar reforçam esse ímpeto de afetação: reconhecimento do princípio da liberdade internacional de navegação nas vias internacionais (rios e lagos compartilhados, canais internacionais); princípio da passagem inofensiva no mar territorial (enquanto que o Estado costeiro exerce sua soberania). A constatação é conhecida, mas em que medida a noção de bem público mundial pode evitar essa tragédia? A noção pode auxiliar na interpretação do termo no sentido da cooperação entre os sujeitos de direito internacional para a gestão dos recursos marinhos.

A cooperação pode ser implementada tanto na Zona, área que está além dos espaços sob a jurisdição dos Es-

44 DUPUY, Pierre-Marie. Droit international public. Paris: Dalloz, 11ème éd. 2012. p. 819.

45 KISS, A. C. La notion de patrimoine commun de l'humanité. RCADI, t. 175, p. 243, 1982.

46 DUPUY, Pierre-Marie. Droit international public. Paris: Dalloz, 11ème éd. 2012. p. 819.

47 DUPUY, Pierre-Marie. Droit international public. Paris: Dalloz, 11ème éd. 2012. p. 819.

48 DUPUY, Pierre-Marie. Droit international public. Paris: Dalloz, 11ème éd. 2012. p. 819. 
tados, quanto nas áreas que estiverem sob a jurisdição dos Estado, mais precisamente, nas Zonas Econômicas Exclusivas. A imprecisão das obrigações específicas nessa área, sobretudo no que tange à atividade de pesca, é evidente tanto para o Estado de bandeira do navio quanto para o Estado costeiro ${ }^{49}$. A opinião consultiva 21 do Tribunal do mar destacou algumas dessas obrigações aplicáveis a sete Estados do continente africano ${ }^{50}$.

No contexto da Convenção relativa à determinação mínima de acesso e de exploração aos recursos pesqueiros no interior das zonas marítimas sob a jurisdição (CMA) dos Estados Membros da Comissão Sub-Regional de Pescas (CSRP), que foi objeto de análise pelo Tribunal do mar na opinião consultiva n. 21, podem ser observadas algumas lacunas no que tange à cooperação dos Estados com relação à pesca ilegal. Há maior previsão de obrigações do Estado costeiro relacionadas à gestão sustentável dos estoques compartilhados e dos estoques de interesse comum, em particular dos tunídeos e de pequenos pelágico, que previsão de obrigações para o Estado de bandeira. Entre as obrigações de gestão sustentável desses recursos pelo Estado costeiro podem ser citadas: a) cooperar sobre as medidas necessárias para assegurar a conservação e o desenvolvimento dos estoques $^{51}$; b) assegurar que não haverá superexploração desses recursos ${ }^{52}$; c) tomar medidas em conformidade com outras organizações que tratem do mesmo tema, como a Comissão internacional para a conservação dos tunídeos do Atlântico tanto nas ZEEs dos Estados membros da CSRP quanto em outros Estados membros de outras organizações que tratem do mesmo tema. Há, ainda, a indicação de que o Estado deve verificar se a preservação e a gestão dos recursos estão sendo feitas de acordo com os dados científicos mais confiáveis dos quais dispõem os Estados membros da CSRP, nos termos do art. 2, parágrafo $2^{\circ}$ da Convenção de Montego Bay ${ }^{53}$.

O caso Virginia G já havia dado maior precisão

49 Ver sobre o tema: KAYE, Stuart. Enforcement Cooperation in Combating Illegal and Unauthorized Fishing: An Assessment of Contemporary Practice. Berkeley J. Int'l L., n. 32, p. 316-329, 2014; TELESETSKY, Anastasia. Laundering Fish in the Global Undercurrents: Illegal, Unreported, and Unregulated Fishing and Transnational Organized Crime. Ecology L.Q., n. 41, p. 939-998, 2014.

50 Cabo Verde, República Islâmica da Mauritânia, Senegal, República da Gâmbia, República da Guiné, República da GuinéBissau e República da Serra Leoa.

51 TRIBUNAL INTERNACIONAL DO DIREITO DO MAR. parágrafo 189. Art. 61.2 da Convenção de Montego Bay.

52 Art. 61.3 da Convenção de Montego Bay.

53 Art. 61.2 da Convenção de Montego Bay. às obrigações do Estado costeiro no que tange à preservação e à gestão dos recursos biológicos na ZEE, elencando as seguintes atividades ${ }^{54}$ : “[...] adotar as leis e os regulamentos que fixem as condições de acesso aos navios de pesca estrangeiros na sua ZEE - arts. 56, parágrafo $1^{\circ}$ e 62 parágrafo $4^{\circ}$ da Convenção". Nos termos do art. 62, parágrafo $4^{\circ}$, essas leis e regulamentos devem ser compatíveis com a Convenção. O tribunal nota que as medidas devem ser de gestão e que não há uma lista exaustiva do que pode ou não ser feito pelo Estado costeiro ${ }^{55}$. No mesmo sentido, a opinião consultiva 21 indica que o Estado costeiro pode adotar “[...] todas as medidas, incluindo de embarque, de inspeção de apreensão e de judicialização que sejam necessárias para assegurar o respeito às leis e aos regulamentos adotados em conformidade com a Convenção" 56 .

Uma grande limitação da cooperação na área da gestão da pesca refere-se ao fato de que não há obrigações gerais para todos os Estados, mas apenas para os Estados membros de comissões de pesca específicas ${ }^{57}$. Essas obrigações reduziriam possíveis efeitos negativos na preservação do meio ambiente marinho considerando que o mar não tem fronteiras. Para que sejam efetivas, as medidas de preservação e de gestão de pesca devem tratar do conjunto de estoque das espécies em toda a zona de distribuição e em todos os itinerários de migração ${ }^{58}$. Os Estados que pescam nos setores adjacentes devem implementar medidas necessárias à preservação desses estoques ${ }^{59}$. Nesse sentido, a noção de bem público mundial pode ressaltar e enfatizar a necessidade de melhor gestão desses recursos tanto no âmbito local quanto no nacional e internacional.

Ademais, os limites da obrigação de cooperar refletem-se no que foi apontado pelo juiz Paik de que a opi-

54 Sobre o tema ver: OLIVEIRA, Carina Costa de; GONÇALVES, Natália da Silva. Comentários ao caso m/v "Virginia" (Panamá c. Guiné-Bissau), 14 de abril de 2014. In: MONEBHURRUN, Nitish. Decisões da corte internacional de justiça e do tribunal internacional sobre o direito do mar. RDI, Brasília, v. 12, n. 2, p. 55-63, 2014.

55 TRIBUNAL INTERNACIONAL DO DIREITO DO MAR. Navio “Virginia G”, Panamá v. Guinée-Bissau, decisão de 14 de abril de 2014, parágrafos 212 e 213.

56 TRIBUNAL INTERNACIONAL DO DIREITO DO MAR. Opinião Consultiva n. 21, parágrafo 105.

57 TRIBUNAL INTERNACIONAL DO DIREITO DO MAR. Opinião consultiva n. 21, parágrafo 69.

58 TRIBUNAL INTERNACIONAL DO DIREITO DO MAR. Opinião consultiva n. 21, parágrafos 196 e 198.

59 TRIBUNAL INTERNACIONAL DO DIREITO DO MAR. Opinião consultiva n. 21, parágrafo 196. 
nião consultiva 21 deveria ter analisado os limites entre a obrigação de cooperar do Estado membro da Comissão de Pesca envolvida na opinião e os direitos do Estado costeiro de preservar e de gerir os recursos biológicos da sua $\mathrm{ZEE}^{60}$. A opinião não garantiu maior precisão com relação à obrigação de cooperar no sentido de que poderia ser um descumprimento dessa obrigação o fato de o Estado se recusar a negociar, demorando para apresentar respostas ou medidas de preservação e de gestão ${ }^{61}$.

Nota-se que os avanços na seara da interpretação da obrigação de cooperação estão vinculados à maior precisão de obrigações específicas de cooperação para todos os Estados no âmbito internacional. Houve avanço, por exemplo, nas obrigações dos Estados costeiros na gestão da pesca ilegal nas áreas sob a jurisdição dos membros da Comissão que solicitou a opinião consultiva n. 21. No entanto, as obrigações gerais de cooperação ainda não contêm maior precisão. Outras áreas, como a liberdade de navegação, também devem ser objeto de análise mais precisa no que tange à preservação dos recursos. Além dos limites do regime de res communis, é relevante avaliar os limites do regime de patrimônio comum da humanidade para fomentar a cooperação no sentido da preservação dos recursos marinhos.

Os limites do regime de patrimônio comum da humanidade

O conteúdo do patrimônio comum da humanidade ${ }^{62}$ ainda é limitado no que concerne à preservação dos recursos marinhos. Em princípio, essa qualificação organiza a gestão comum teoricamente sustentável dos recursos sob esse regime ${ }^{63}$. Para avaliar os limites desse regime

60 TRIBUNAL INTERNACIONAL DO DIREITO DO MAR Opinião individual do juiz Paik, parágrafo 31.

61 TRIBUNAL INTERNACIONAL DO DIREITO DO MAR. Opinião individual do juiz Paik, parágrafo 37.

62 Ver sobre o tema: KISS, A. C. La notion de patrimoine commun de l'humanité. RCADI, t. 175, p. 103, 1982 e s; LODGE, Michael W. The Common Heritage of Mankind. The International Journal of Marine and Coastal Law, n. 27, p. 733-742, 2012; NOYES, John E. The common heritage of mankind: past, present, and future. Denv. J. Int'l L. \& Pol'y, n. 20, p. 447, 2011-2012; BASLAR, Kemal. The Concept of the Common Heritage of Mankind in International Law. Hague: Nijhoff Publishers, 1998; SHACKELFORD, Scott J. The Tragedy of the Common Heritage of Mankind. Stan Envtl LJ, n. 28, 2009; JOYNER, C. Legal Implications of the Concept of the Common Heritage of Mankind. Int'l \& Comp. LQ, n. 35, 1986; BARDONNET, D. Le projet de convention de 1912 sur le Spitsberg et le concept de patrimoine commun de l'humanité. Mélanges René-Jean Dupuy. In: HUMANITÉ et droit international. Paris: Pedone, 1991. p. 13.

63 O espaço terrestre (Antártica), o espaço extratosférico, o es- jurídico para a preservação dos recursos marinhos, com um conteúdo de cooperação para a gestão do bem, devem ser analisados o conceito de patrimônio comum da humanidade, os limites desse conteúdo para garantir a cooperação na gestão dos recursos marinhos e o exemplo dos limites da qualificação da Antártica e do Ártico.

O conceito de patrimônio comum da humanidade aplicado aos fundos marinhos foi tratado pela primeira vez pelo Embaixador de Malta na Assembleia Geral da $\mathrm{ONU}^{64}$. A Convenção de Montego Bay (1982) estabeleceu regime internacional de gestão dos fundos em benefício da humanidade sob a gestão da Autoridade para os fundos marinhos. No entanto, o Acordo de implementação de 1994 esvaziou o conteúdo da parte XI da Convenção de Montego Bay. Esse acordo foi necessário em razão da oposição de alguns Estados desenvolvidos de ratificar a Covenção que finalmente entrou em vigor em $1995^{65}$. Não se sabe, portanto, de que forma os princípios da Convenção serão aplicados.

Por sua vez, o tribunal de direito do mar testemunhou, por meio de opinião consultiva, a sua posição de que tem o objetivo de dar um conteúdo substancial ao regime do patrimônio comum da humanidade ${ }^{66}$. Nesse sentido, podem ser indicados como exemplo os parágrafos seguintes: "O papel do Estado patrocinador, tal como foi anunciado na Convenção, é de contribuir com a realização do interesse comum de todos os Estados por meio da aplicação correta do princípio do patrimônio comum da humanidade, o que necessita configurar de modo fidedigno as obrigações anunciadas na parte $\mathrm{XI}^{\prime{ }^{67}}$. Cita-se, ainda, a seguinte passagem:

no contexto da obrigação dos Estados de auxiliarem a Autoridade que age representando a humanidade, quando ele determina quais são as medidas razoavelmente apropriadas, o Estado patrocinador tem de ter em conta de modo objetivo as opções

paço da lunar e o espaço marinho. EDELMAN, B. Entre personne humaine et matériau humain : le sujet de droit. In: HERMITTE, M.-A., EDELMAN, B.: L'homme, la nature et le droit. Paris: Bourgois, 1988. p. 136 ; KISS, A. C. La notion de patrimoine commun de l'humanité. RCADI, t. 175, p. 103, 1982. e s.

64 Ver a Resolução 2749 (XXV) de 16 de dezembro de 1970.

65 DUPUY, Pierre-Marie. Droit international public. Paris: Dalloz, 11 ème éd. 2012. p. 741.

66 TRIBUNAL INTERNACIONAL DO DIREITO DO MAR. Câmara para a resolução de controvérsias relacionadas aos fundos marinhos, Opinião consultiva n. 17 do dia $1^{\circ}$ fevereiro 2011, "Responsabilidade e obrigações dos Estados que patrocinam as pessoas e as entidades no contexto das atividades realizadas na Zona".

67 TRIBUNAL INTERNACIONAL DO DIREITO DO MAR. Opinião consultiva n. 17, parágrafo 76. 
que se apresentam de modo razoável, oportuna e favorável à toda a humanidade. Ele deve agir de boa-fé, em particular quando os seus atos possam prejudicar os interesses de toda a humanidade ${ }^{68}$.

A sua aplicação também foi invocada no contexto da Antártica. Entretanto, os Estados signatários do tratado de Washington se recusaram a passar do conceito de interesse comum para o conceito de patrimônio comum da humanidade. No preâmbulo da Convenção de Camberra, bem como no preâmbulo do Protocolo de Madri, o interesse da humanidade é reafirmado na motivação das Partes contratantes, mas sem existir nenhuma referência à noção de patrimônio comum. Este parece dificilmente conciliável com as reivindicações de soberania dos Estados que se entendem possuidores da região $0^{69}$. Na prática, no entanto, isso não impede que os Estados adotem regras de proteção mais rigorosas que pareçam em seu conteúdo àquelas que qualificam o patrimônio comum da humanidade ${ }^{70}$.

No Ártico, sabe-se que as mudanças climáticas abrem novas perspectivas para a navegação e para a exploração de petróleo. A questão de domínio dessa área voltou ao debate. A Declaração de Illulissat, adotada por cinco Estados ribeirinhos (Canadá, Dinamarca, Estados-Unidos, Noruega e Rússia) durante a conferência sobre o oceano Ártico, no dia 28 de maio de 2008, exclui uma apropriação do oceano Ártico pelos Estados ribeirinhos. Ao mesmo tempo, a Conferência afastou a perspectiva de elaboração de um regime jurídico internacional específico para a aplicação de um direito comum do mar para a região.

Percebe-se que o regime de patrimônio comum da humanidade é limitado no que concerne à implementação da obrigação de cooperação para a gestão dos recursos marinhos. Mesmo que esse regime tenha sido elaborado antes da moda dos bens públicos mundiais, é relevante buscar uma operacionalização desse termo por meio da previsão de obrigações específicas conectadas à cooperação dos sujeitos de direito internacional.

Além da obrigação de cooperar, a obrigação de due diligence requer análise específica de seus limites para a preservação dos recursos marinhos.

68 TRIBUNAL INTERNACIONAL DO DIREITO DO MAR. Opinião consultiva n. 17, parágrafo 230. Ver, ainda, o parágrafo 122. 69 GUILLAUME, G. Le statut de l'Antarctique. Refléxions sur quelques problèmes récents. In: MÉLANGES offert à René-Jean Dupuy, 1991. p. 174. 70 Esse aspecto está refletido no Protocolo de Madri.

\section{Os LIMITES DA IMPLEMENTAÇÃO DA OBRIGAÇÃO DE DUE DILIGENCE PARA A PRESERVAÇÃO DO MEIO AMBIENTE MARINHO}

A obrigação de due diligence ${ }^{71}$ sugere o maior direcionamento dos sujeitos de direito internacional para a gestão dos recursos marinhos, mas ainda com diversos limites. As obrigações de due diligence representam a obrigação dos Estados de adotarem instrumentos substancias e processuais relacionados ao controle das atividades que estão sob a sua gestão. É relevante examinar o seu conceito, a sua variabilidade e as críticas relacionadas à dificuldade de implementação dessas obrigações no sentido da preservação dos recursos marinhos.

Os Estados possuem obrigações de due diligence no que se refere a diversas atividades no mar tanto em áreas sob a sua jurisdição quanto nos espaços que não estão sob a sua jurisdição. Espera-se dos Estados e das Organizações Internacionais (OIs) condutas que evitem a emergência de possíveis danos. Trata-se de obrigação de conduta, o que já foi indicado em decisões e em opiniões consultivas da no âmbito da Corte Internacional de Justiça (CIJ) e do Tribunal Internacional do Direito do Mar. Na decisão de 20 de abril de 2010 no caso Papeleiras, a CIJ avaliou que:

[...] observa que o princípio da prevenção, sendo uma regra costumeira, possui a sua origem na diligência requerida ('due diligence') do Estado sobre o seu território. Trata-se de uma obrigação, de todos os Estados, de não utilizar o seu território com finalidades contrárias aos direitos de outros Estados (Détroit de Corfou, Royaume-Uni c. Albanie, decisão 1949, p. 22) ${ }^{72}$. [...] O Estado deve utilisar todos os meios à sua disposição para evitar que as atividades que ocorram no seu território ou em todo espaço que esteja sob a sua jurisdição não causem prejuízo ao meio ambiente de um outro Estado. A Corte estabeleceu que essa obrigação faz parte do corpo de regras do direito internacional do meio ambiente ${ }^{73}$.

71 TRIBUNAL INTERNACIONAL DO DIREITO DO MAR. Opinião consultiva n. 17, parágrafos 117 a 120 . Disponível em: <https://www.itlos.org/fileadmin/itlos/documents/cases/ case_ no_17/17_adv_op_010211_en.pdf >.

72 CORTE INTERNACIONAL DE JUSTIÇA. Caso Papeleras no Rio Uruguai (Argentina v. Uruguai). Julgamento de 20 de Abril de 2010, parágrafo 187, “[...] observe que le principe de prévention, en tant que règle coutumière, trouve son origine dans la diligence requise ('due diligence') de l'État sur son territoire. Il s'agit de 'l'obligation, pour tout État, de ne pas laisser utiliser son territoire aux fins d'actes contraires aux droits d'autres États' (Détroit de Corfou (RoyaumeUni c. Albanie), fond, arrêt, C.I.J. Recueil 1949, p. 22)".

73 CORTE INTERNACIONAL DE JUSTIÇA. Caso Papeleras 
As obrigações de due diligence também foram citadas nas opiniões consultivas n. $17^{74}$ e $21^{75}$ do Tribunal Internacional de Direito do Mar com o mesmo sentido do que foi interpretado no âmbito da CIJ.

Observa-se que o conceito de due diligence é variável ${ }^{76}$. $\mathrm{Na}$ análise da forma pela qual o Estado tenha sido ou não diligente serão levadas em consideração as condições do Estado para cumprir essas obrigações ${ }^{77}$. O problema dessa variação consiste em identificar qual seria o conteúdo mínimo de diligência que poderia ser exigida de todos os Estados no que tange à preservação dos recursos marinhos. Diante dos limites da contribuição da interpretação das obrigações de due diligence para a preservação dos recursos marinhos, é relevante analisar

no Rio Uruguai (Argentina v. Uruguai). Julgamento de 20 de Abril de 2010, parágrafo 101, "En effet, l'État est tenu de mettre en œuvre tous les moyens à sa disposition pour éviter que les activités qui se déroulent sur son territoire, ou sur tout espace relevant de sa juridiction, ne causent un préjudice sensible à l'environnement d'un autre État. La Cour a établi que cette obligation 'fait maintenant partie du corps de règles du droit international de l'environnement". Pode ser citado o parágrafo 197: "Cette obligation implique la nécessité non seulement d'adopter les normes et mesures appropriées, mais encore d'exercer un certain degré de vigilance dans leur mise en œuvre ainsi que dans le contrôle administratif des opérateurs publics et privés, par exemple en assurant la surveillance des activités entreprises par ces opérateurs, et ce, afin de préserver les droits de l'autre partie. Par conséquent, la responsabilité d'une partie au statut de 1975 serait engagée s'il était démontré qu'elle n'avait pas agi avec la diligence requise, faute d'avoir pris toutes les mesures appropriées pour assurer l'application de la réglementation pertinente à un opérateur public ou privé relevant de sa juridiction" Usinas de papel no rio Uruguai".

74 Na opinião consultiva do Tribunal do Mar sobre a responsabilidade e as obrigações dos Estados no contexto das atividades realizadas na Zona, a obrigação de due diligence foi identificada como possuindo um conteúdo variável: "Il est difficile de décrire en des termes précis le contenu des obligations de « diligence requise . Parmi les facteurs qui rendent une telle description ardue figure le fait que la notion de diligence requise a un caractère variable. Elle peut changer dans le temps lorsque les mesures réputées suffisamment diligentes à un moment donné peuvent ne plus l'être en fonction, par exemple, des nouvelles connaissances scientifiques ou technologiques. Cette notion peut également changer en fonction des risques encourus par l'activité. [...] Le niveau de diligence requise doit être plus rigoureux pour les activités les plus risquées. (TRIBUNAL INTERNACIONAL DO DIREITO DO MAR, Opinião consultiva n. 17 , parágrafo 117 ).

75 TRIBUNAL INTERNACIONAL DO DIREITO DO MAR. Pedido de Opinião Consultiva feita pela Comissão Sub-regional de pesca (SRFC). Opinião consultiva n. 21, de 2 de april de 2015, parágrafos 131 a 139. Disponível em: < https://www.itlos.org/ fileadmin/itlos/documents/cases /case_no.21/advisory_opinion/ C21_AdvOp_02.04.pdf $>$.

76 TRIBUNAL INTERNACIONAL DO DIREITO DO MAR. Opinião consultiva n. 17, parágrafo 117.

77 TRIBUNAL INTERNACIONAL DO DIREITO DO MAR. Opinião consultiva n. 17, parágrafo 117. os exemplos dos limites da preservação dos recursos pesqueiros em áreas sob a jurisdição dos Estados e os limites do regime do patrimônio comum da humanidade para a preservação dos recursos marinhos.

Os limites da preservação dos recursos pesqueiros em área sob a jurisdição dos Estados

As obrigações de due diligence são insuficientes para garantir a devida preservação dos recursos pesqueiros em área sob a jurisdição dos Estados. A opinião consultiva n.21 do Tribunal do Mar, que abordou a responsabilidade do Estado de bandeira pela pesca ilícita, constitui exemplo interessante, pois está em conformidade com os tratados aplicáveis à matéria e com os precedentes relacionados à interpretação das obrigações de due diligence dos Estados. Além disso, ela evidencia os limites dessas obrigações para a preservação dos recursos marinhos.

A opinião consultiva n. 21 interpretou as obrigações de due diligence com relação à pesca na área sob a jurisdição dos Estados. O tribunal do mar, antes de analisar as questões substanciais do pedido da opinião consultiva, definiu o que se entende por pesca ilícita, não declarada e não regulamentada ${ }^{78}$, e o que significa a preservação dos recursos biológicos na ZEE dos Estados membros da Comissão previamente citada ${ }^{79}$. Outras definições importantes foram de navio de pesca $^{80}$, de estoques compartilhados ${ }^{81}$ e de estoques de interesse comum ${ }^{82}$.

78 As definições de pesca ilícita, pesca não declarada e pesca não regulamentada estão previstas no art. 2, parágrafo $4^{\circ}$ da CMA. A opinião consultiva lembrou que essas definições foram inspiradas no Plano de ação internacional visando a prevenir e a eliminar esse tipo de pesca, elaborado e adotado em 2001 pela FAO. Disponível em: <http://www.fao.org/docrep/003/y1224e/y1224e00.htm>. Acesso em: 15 maio 2015; e no Acordo relativo às medidas tomadas pelo Estado do Porto visando a prevenir e a eliminar a pesca ilícita, adotado em 2009. Disponível em: < http:/ / www.fao. org/fishery/topic/166283/en Parágrafo 91>. Acesso em: 15 maio 2015.

79 Cabo Verde, República Islâmica da Mauritânia, Senegal, República da Gâmbia, República da Guiné, República da Guiné-Bissau e República da Serra Leoa. TRIBUNAL INTERNACIONAL DO DIREITO DO MAR. Opinião Consultiva n. 21, parágrafo 189, 191. A expressão é utilizada para significar conservação, desenvolvimento. O tribunal afirma que o art. 61 da Convenção dá algumas indicações do que seria a gestão sustentável.

80 TRIBUNAL INTERNACIONAL DO DIREITO DO MAR. Opinião Consultiva n. 21, parágrafo 99.

81 TRIBUNAL INTERNACIONAL DO DIREITO DO MAR. Opinião Consultiva n. 21, parágrafo 184: "Le Tribunal observe que ces expressions ne figurent pas dans la Convention. Toutefois, l'expression stocks partagés est définie à l'article 2, paragraphe 12, de la Convention CMA comme signifiant les stocks de poissons se trouvant dans les zones maritimes sous juridiction de deux ou plusieurs Etats côtiers ou à la fois à l'intérieur de la zone maritime sous juridiction et dans un secteur adjacent à cette zone".

82 TRIBUNAL INTERNACIONAL DO DIREITO DO MAR, Opinião Consultiva n. 21, parágrafo 185: 'Le Tribunal observe qu'il 
De modo geral, os navios de pesca devem obter autorização do Estado membro da Comissão para que fique estabelecida a cota de pesca possível. Para tanto, o navio deve apresentar no porto desse Estado as declarações de captura indicadas no seu diário de pesca e não pode utilizar materiais ilegais para a sua atividade. $O$ navio deve notificar o Estado costeiro da sua entrada e da sua saída do espaço marítimo sob a jurisdição de um dos Estados membros da Comissão ${ }^{83}$.

De acordo com o tribunal, o Estado de bandeira do navio teria obrigações de due diligence relacionadas à pesca ilegal ${ }^{84}$. Podem ser citadas as seguintes obrigações específicas: a) tomar as medidas necessárias para verificar se os navios de sua bandeira estão em conformidade com as leis e os regulamentos adotados pelos Estados membros da CSRP com relação aos recursos biológicos marinhos que estiverem em suas $Z_{E E} E^{85}$; b) verificar se os navios com a sua bandeira não realizam atividades ligadas à pesca não regulamentada nas ZEEs dos Estados membros da comissão $0^{86}$; c) adotar as medidas administrativas necessárias para verificar se os navios de pesca com bandeiras nacionais não realizam atividades que contrariem a preservação do meio ambiente marinho e a conservação dos recursos biológicos $\operatorname{marinhos}^{87}$; d) permitir a subida à bordo das autoridades do Estado costeiro que pretendam investigar e controlar as atividades de pesca.

Como foi analisado na opinião consultiva, a pesca ilícita pode resultar na responsabilização do Estado de bandeira apenas no caso de descumprimento das citadas obrigações de due diligence. A obrigação de re-

n'y a pas de définition établie de stocks d'intérêt commun. Il note toutefois que, dans l'exposé qu'elle a fait au cours de la procédure orale, la CSRP a donné l'explication suivante s'agissant de l'expression stocks d'intérêt commun: Au niveau de l'Atlantique Centre-Est, plusieurs espèces de pélagiques migrent entre les Zones économiques exclusives de deux ou plusieurs Etats (transfrontaliers ou stocks d'intérêt commun) et/ ou entre des Zones économiques exclusives et les eaux au-delà (stocks chevauchants). Il s'agit donc de stocks partagés entre : deux Etats côtiers voisins, deux Etats côtiers non voisins situés de part et d'autre d'un golfe ou d'un océan ou un Etat côtier et l'Etat du pavillon de l'exploitant du stock".

83 TRIBUNAL INTERNACIONAL DO DIREITO DO MAR. Opinião Consultiva n. 21, parágrafo 113.

84 TRIBUNAL INTERNACIONAL DO DIREITO DO MAR. Opinião Consultiva n. 21, parágrafos 125- 132.

85 TRIBUNAL INTERNACIONAL DO DIREITO DO MAR. Opinião Consultiva n. 21, parágrafo 114.

86 TRIBUNAL INTERNACIONAL DO DIREITO DO MAR. Opinião Consultiva n. 21, parágrafo 114.

87 TRIBUNAL INTERNACIONAL DO DIREITO DO MAR. Opinião Consultiva n. 2, Parágrafos 116, 138. sultado não pode ser determinada sem a análise prévia da obrigação de comportamento ${ }^{88}$. Se o Estado de bandeira tiver adotado todas as medidas necessárias e apropriadas para cumprir as suas obrigações de conduta, ele não será responsabilizado pelos eventuais danos causados ao meio ambiente marinho. Esse é um dos principais limites das obrigações dos Estados por due diligence. Apesar de ter existido maior precisão do conteúdo das obrigações relacionadas à pesca ilegal, ainda há limitação na transposição dessa análise para a garantia de uma gestão adequada dos recursos marinhos por meio de obrigações de comportamento e de resultado. Além desse tema, cabe o estudo dos limites do regime do patrimônio comum da humanidade para a preservação dos recursos marinhos.

b) Os limites do regime do patrimônio comum da humanidade para a preservação dos recursos marinhos

As obrigações de due diligence dos Estados e das OIs ainda não estão bem delimitadas no que concerne à gestão dos fundos marinho. Tendo como base a perspectiva de bem público mundial, no que tange à ampliação do conteúdo da patrimonialização para um conteúdo de gestão, poderá existir maior implementação de obrigações conectadas à preservação dos recursos marinhos. Assim, apresentar-se-á o contexto da exploração e da investigação dos fundos marinhos, a articulação entre as obrigações de due diligence e a preservação dos fundos marinhos e os limites dessas obrigações para chegar ao objetivo citado.

O contexto das atividades nos fundos marinhos é de que ainda não há contratos de explotação (exploitation), mas há alguns contratos de exploration ${ }^{89}$ de sulfetos polimetálicos ${ }^{90}$. A despeito da potencialidade ainda indeterminada dos danos no âmbito da investigação, e da inexistência de casos concretos julgados sobre danos decorrentes dessas atividades, já há indicação de obrigações diretas dos Estados perante a Autoridade dos fundos marinhos ${ }^{91}$ e dos critérios da obrigação de due

88 TRIBUNAL INTERNACIONAL DO DIREITO DO MAR. Opinião Consultiva n. 21, parágrafo 129.

89 No sentido de investigação comercial, de prospecção.

90 Autoridade para os fundos marinhos. Status of contracts for exploration in the Area. Twenty-First Session Official Documents. ISBA/21/C/8. Kingston, Jamaica, 2 junho de 2015. Disponível em: <https://www. isa.org.jm/sites/default/files/files/documents/isba-21c-8_1.pdf>. Acesso em: 20 jun. 2015.

91 Entre as obrigações diretas dos Estados, podem ser citadas obrigações indicadas nas Regulações elaboradas pela Autoridade dos Fundos Marinhos e obrigações previstas na Convenção de Mon- 
diligence que devem ser observados pelos Estados. A implementação das obrigações de due diligence no contexto dos fundos marinhos pode ser configurada no direcionamento do Estado "patrocinador" no controle e na regulação dos operadores públicos e privados que exploram e que investigam os fundos marinhos.

Sobre o tema, a opinião consultiva n. 17 do Tribunal do mar esclareceu alguns aspectos relacionado à responsabilidade do Estado patrocinador. O tribunal entendeu que o Estado tem a obrigação de conduta de criar normas e regulamentos para garantir que a empresa contratante siga um corpo normativo ambiental mínimo. Entre as medidas de prevenção que devem ser adotadas pelo Estado, podem ser citadas a exigência de estudo de impacto ambiental ${ }^{92}$ e a existência de um corpo normativo que garanta a implementação da obrigação de reparar o dano em caso de descumprimento ${ }^{93}$. Não é suficiente a realização de um contrato de exploração com a empresa pública ou privada. Deve existir arcabouço

tego Bay. Pode ser citada a Regulação de Nódulos Polimetálicos de 2010 e a Regulação de Sulfetos Polimetálicos de 2010. A esse respeito ver: AUTORIDADE INTERNACIONAL DE FUNDOS MARINHOS. Decision of the Assembly of the International Seabed Authority relating to regulations on prospecting and exploration for polymetallic sulphides in the Area. ISBA/16/A/12/Rev.1. Sixteenth Season Official Documents. Kingston, Jamaica. 15 nov. 2010. Disponível em: <http://www.isa.org.jm/files/documents/EN/16Sess/Assembly/ ISBA-16A-12Rev1.pdf>. Acesso em: 10 jun. 2015. Além disso, outra regulação que é citada com frequência é a seguinte: AUTORIDADE INTERNACIONAL DE FUNDOS MARINHOS. Decision of the Council of the International Seabed Authority relating to amendments to the Regulations on Prospecting and Exploration for Polymetallic Nodules in the Area and related matters. ISBA/19/C/17. Nineteenth Season Official Documents. Kingston, Jamaica, 22 julho de 2013. Disponível em: < https://www.isa.org.jm/sites/default/files/files/documents/ isba-19c-17_0.pdf>. Ver sobre o tema: TRIBUNAL INTERNACIONAL DO DIREITO DO MAR. Opinião consultiva n. 17, parágrafos 121 a 140. Disponível em: <https://www.itlos.org/fileadmin/itlos/documents/cases/ case_no_17/17_adv_op_010211_ en.pdf $>$. Acesso em: 10 jun. 2015.

92 Ver parágrafo 148 da opinião consultiva que indica que o Estudo de Impacto Ambiental não deve ser entendido como um costume em direito internacional ambiental. O EIA deve ser requerido no momento de consultas e de notificações, nos termos do art. 142 da Convenção de Montego Bay. Essa obrigação está relacionada, portanto, ao direito interno dos Estados. Ver sobre o tema: Case note: "Responsibilities and obligations of states sponsoring persons and entities with respect to activities in the area: the international tribunal of the law of the sea's recent contribution to international environmental law". RECIEL 20 (2) 2011, p. 211.

93 Ver sobre o tema: LIMA, Gabriela Garcia B. Caso do Parecer consultivo do Tribunal Internacional de Direito do Mar de $1^{\circ}$ de fevereiro de 2011. In: MONEBHURRUN, Nitish. Decisões da corte internacional de justiça e do tribunal internacional sobre o direito do mar. RDI, Brasília, v. 12, n. 2, p. 20-26, 2014. normativo capaz de responsabilizar devidamente a empresa pública ou privada por eventuais danos causados pela exploração. Caso a empresa tenha a nacionalidade de outro país, é necessário que o seu Estado de origem também assine o plano de trabalho, sujeitando-se a eventual responsabilização.

A opinião consultiva afirmou que o Estado patrocinador não pode ser responsabilizado pelos atos de suas empresas quando tiver tomado as medidas que lhe eram razoavelmente exigíveis, isto é, tenha procedido com a devida diligência ${ }^{94}$. Observa-se que uma das maiores dificuldades consiste em poder responsabilizar um Estado pelo descumprimento de uma obrigação de due diligence. As obrigações não são tão específicas e deixam margem à uma avaliação indevida do conteúdo mínimo necessário para demonstrar o cumprimento dessas obrigações. Se o Estado demonstrar que foi diligente, ele não será responsabilizado subsidiariamente pelos eventuais danos causados pela empresa patrocinada, de acordo com o que foi estabelecido pela opinião consultiva ${ }^{95}$. Ou seja, caso a diligência fique provada, o Estado não será responsabilizado pelos eventuais danos ambientais que ocorrerem. Trata-se de limitação para a preservação ambiental, pois não apenas as obrigações de conduta devem ser consideradas para a responsabilização do Estado, mas também as obrigações de resultado. Há limites consideráveis para que o conteúdo de gestão dos chamados bens públicos mundiais possa resultar em uma possível responsabilização do Estado pela falta de preservação do meio ambiente marinho.

\section{Considerações finais}

Apesar de o termo bem público mundial não ser operatório e jurídico, ele destaca a falta de precisão, no âmbito do direito internacional, das obrigações específicas dos sujeitos de direito internacional no que tange à preservação dos recursos marinhos. As questões globais requerem respostas internacionais e nacionais, mas poucas obrigações internacionais exigem que os Estados forneçam e implementem essas respostas. É

94 TRIBUNAL INTERNACIONAL DO DIREITO DO MAR. Opinião n. 17, parágrafos 213 a 217. Disponível em: https://www. itlos.org/fileadmin/itlos/documents/cases/ case_no_17/17_adv_ op_010211_en.pdf. Acesso em: 15 jun. 2015.

95 TRIBUNAL INTERNACIONAL DO DIREITO DO MAR. Opinião Consultiva no. 17, parágrafos 204. 
conveniente questionar se as categorias ou os instrumentos do direito internacional, consolidadas no direito do mar, são capazes de garantir a devida preservação dos recursos marinhos. Alguns aspectos tornaram-se evidentes nessa análise: o valor interpretativo do bem público mundial; o conteúdo limitado dos regimes de res communis e de patrimônio comum da humanidade para a preservação dos recursos marinhos; a necessidade de maior precisão do conteúdo das obrigações de cooperar e das obrigações de due diligence tanto na sua aplicação em âmbito nacional quanto em internacional.

O bem público mundial não tem capacidade de gerar efeitos jurídicos, atualmente, e não há indícios de que ele o faça em breve. Uma das possíveis contribuições do termo para a preservação dos recursos marinhos é de caráter interpretativo, contribuindo para a apreciação de institutos jurídicos já consolidados no direito internacional. O conteúdo do bem público mundial de cooperação é o aspecto central que deve pautar a gestão desses recursos. As categorias jurídicas mais próximas do conceito de bem público mundial são o bem comum e o patrimônio comum da humanidade. Todavia, ambos os institutos estão mais conectados à internacionalização e à patrimonialização do que à gestão, o que os distancia da implementação da obrigação de cooperar e de prevenir no direito internacional.

Tanto a obrigação de cooperar quanto a obrigação de due diligence, ambas consolidadas no direito internacional, possuem conteúdo impreciso no que tange à preservação dos recursos marinhos. Como os recursos vivos e não vivos estão presentes nas áreas sob jurisdição nacional e internacional, as obrigações dos Estados nos dois âmbitos devem ser mais precisas e detalhadas para que sejam operacionalizáveis diante de tribunais nacionais e internacionais.

O desafio, portanto, é utilizar os regimes jurídicos já existentes, como a res communis ou o patrimônio comum da humanidade, com um conteúdo mais preciso e conectado às obrigações ligadas à preservação dos recursos marinhos. Caso a ampliação dessa interpretação não seja possível, o conceito de bem público mundial pode ser útil na condução dos Estados na implementação de medidas específicas para a conservação dos recursos marinhos que estiverem sob a sua jurisdição, como na Zona Econômica Exclusiva. A atividade que demonstra contornos mais precisos e mais claros com relação a essas obrigações de cooperar e de diligência é a pesca que já foi objeto de in- terpretações do Tribunal Internacional para o Direito do Mar. Outras atividades, como a navegação e a exploração de recursos nos fundos marinhos, ainda requerem maior precisão no que concerne às obrigações específicas conectadas à preservação dos recursos marinhos.

\section{ReferênCias}

AGENCIA FRANCESA DE DESENVOLVIMENTO. Biens publics mondiaux et développement : de nouveaux arbitrages pour l'aide ?. Documento de trabalho n. 3, Paris, sept. 2005.

BANCO MUNDIAL. Effective Use of Development finance for International Public Goods. Global Development Finance, Washington DC, 2001.

BARDONNET, D. Le projet de convention de 1912 sur le Spitsberg et le concept de patrimoine commun de l'humanité. Mélanges René-Jean Dupuy. In: HUMANITÉ et droit international. Paris: Pedone, 1991.

BARRETT, Scott. Why Cooperate? The Incentive to Supply Global Public Goods. Oxford: Oxford University Press, 2007.

BASLAR, Kemal. The Concept of the Common Heritage of Mankind in International Law. Hague: Nijhoff Publishers, 1998.

BENZING, Markus. Community Interests in the Procedure of International Courts and Tribunals. The Law and Practice of International Courts and Tribunals, n. 5, p. 369-408, 2006.

BODANSKY, Daniel. What's in a Concept? Global Public Goods, International Law, and Legitimacy. The European Journal of International Law, v. 23, n. 3, p. 651-668, 2012.

BOIDIN, Bruno. La santé, bien public mondial ou bien marchand: réflexions à partir des expériences africaines. Villeneuve d'Ascq: Presses Universitaires du Septentrion, 2014.

CAFAGGI Fabrizio, CARON, David D. Global Public Goods amidst a Plurality of Legal Orders: A Symposium. The European Journal of International Law, v. 23, n. 3, p. 643-649, 2012.

CAFAGGI, Fabrizio. Private regulation and the production of global public goods and private 'bads'. The European Journal of International Law, v. 23, n. 3, p. 695718, 2012. 
DEBLOCK, Christian; DELAS, Olivier. Le bien commun comme réponse politique à la mondialisation. Bruxelles: Bruylant, 2003.

DUPUY, Pierre-Marie. Droit international public. Paris: Dalloz, 11 ème éd. 2012.

EDELMAN, B. Entre personne humaine et matériau humain : le sujet de droit. In: HERMITTE, M.-A., EDELMAN, B.: L’homme, la nature et le droit. Paris: Bourgois, 1988.

FAUCHEUX S.; NOËL, J. F. Les menaces globales sur l'environnement, Paris: Repères La Découverte, 1990.

FRANCKX, Erik. The International Seabed Authority and the Common Heritage of Mankind: The Need for States to Establish the Outer Limits of their Continental Shelf. The International Journal of Marine and Coastal Law, n. 25, p. 543-567, 2010.

GARTNER, David. Global public goods and global health. Duke J. Comp. \& Int'l L., n. 22 (303), 2011-2012.

GIDEL, Gilbert. Le droit international Public de la Mer. Recueil Sirey. 1934. Tomo I, II e III.

GORDILLO, José Luis. La Protección de los bienes comunes de la humanidad: un desafío para la política y el derecho del siglo XXI. Madrid: Editorial Trotta, 2006.

GUILLAUME, G. Le statut de l'Antarctique. Refléxions sur quelques problèmes récents. In: MÉLANGES offert à RenéJean Dupuy, 1991.

HARDIN, Garrett. The Tragedy of the Commons. Science 13, v. 162, p. 1243-1248, dez. 1968. HEATHCOTE, S. Les biens publics mondiaux et le droit international. Quelques réflexions à propos de la gestion de l'intérêt commun. L'Observateur des Nations Unies, n. 13, p. 143, 2002.

HELLER, M. A. The Tragedy of the Anticommons: Property in the Transition from Marx to Markets. Harvard Law Review, 111, p. 622, 1998.

JOUANNET, E. L'idée de communauté humaine. In: ARCHIVES dephilosophie du droit. La mondialisation entre illusion et utopia. t. 47, p. 191.

JOYNER, C. Legal Implications of the Concept of the Common Heritage of Mankind. Int'l \& Comp. LQ, n. 35, 1986.

KAUL I.; GRUNBERG, I.; STERN, M. A. International
Cooperation in the 21st Century. Oxford: Oxford University Press, 1999.

KAUL, Inge et al. Providing Global Public Goods; Managing Globalization. New York: Oxford University Press, 2003.

KAYE, Stuart. Enforcement Cooperation in Combating Illegal and Unauthorized Fishing: An Assessment of Contemporary Practice. Berkeley J. Int'l L., n. 32, p. 316-329, 2014.

KISS, A. C. La notion de patrimoine commun de l'humanité. RCADI, t. 175, 1982.

KRISCH, Nico. The decay of consent: international law in an age of global public goods. The American Journal of International Law, v. 108, n. 1, p. 1-40, jan. 2014.

KU, Charlotte. The Concept of Res Communis in International Law. History of European Ideas, v. 12, n. 4, 1990.

LIMA, Gabriela Garcia B. Caso do Parecer consultivo do Tribunal Internacional de Direito do Mar de $1^{\circ}$ de fevereiro de 2011. In: MONEBHURRUN, Nitish. Decisões da corte internacional de justiça e do tribunal internacional sobre o direito do mar. RDI, Brasília, v. 12, n. 2, p. 20-26, 2014.

LODGE, Michael W. The Common Heritage of Mankind. The International Journal of Marine and Coastal Law, n. 27, p. 733-742, 2012.

LOGEAT, C. Les biens privés affectés à l'utilité publique. Paris: L'harmattan, 2011.

MALJEAN-DUBOIS, Sandrine. The Role of International Law in the Promotion of the Precautionary Principle. Disponível em <http://www.iales-aides. com/uploads/1/3/9/6/13963183/the_role_of_international_law_in_the_promotion_of_the_precautionary_principle_-_sandrine_maljean-dubois.pdf $>$. Acesso em: 15 jun. 2015.

MALJEAN-DUBOIS, Sandrine; KERBRAT, Yann. La Cour Internationale de Justice face aux enjeux de protection de l'environnement : réflexions critiques sur l'arrêt du 20 avril 2010 , Usines de pâte à papier sur le fleuve Uruguay (Argentine c. Uruguay). RGDIP, n. 1, t. CXV, p. 39-75, 2011.

MARR, Simon. The Southern Bluefin Tuna Cases: The Precautionary Approach and Conservation and Management of Fish Resources. European Journal of International Law, v. 11, n. 04, p. 815-831, 2000. 
MAVROIDIS, Petros C. Free Lunches? WTO as Public Good, and the WTO's View of Public Goods. The European Journal of International Law, v. 23, n. 3, p. 731-742, 2012.

MELLO, Celso D. De Albuquerque. Alto-mar. Rio de Janeiro: Renovar, 2001.

MERCURE, P. F. L'échec des modèles de gestion des ressources naturelles selon les caractéristiques du concept de patrimoine commun de l'humanité. Revue de droit d'Ottawa. Ottawa Law Review, v. 28, 1996- 1997.

MEYER, Timothy. Global public goods, governance risk and international energy. Duke J. Comp. \& Int'l L., v. 22, n. 319, 2011-2012.

NOLLKAEMPER, André. International Adjudication of Global Public Goods: The Intersection of Substance and Procedure. The European Journal of International Law, v. 23 n. 3, p. 769-791, 2012.

NOYES, John E. The common heritage of mankind: past, present, and future. Denv. J. Int'l L. \& Pol'y, n. 20, p. $447,2011-2012$.

OLIVEIRA, Liziane Paixão Silva; MARINHO, Maria Edelvacy. O caso Austrália c. Japão perante a Corte Internacional de Justiça, Decisão, 31 de março de 2014. In: MONEBHURRUN, Nitish. Decisões da corte internacional de justiça e do tribunal internacional sobre o direito do mar. RDI, Brasília, v. 12, n. 2, p. 43-49, 2014.

OLIVEIRA, Carina Costa de; GONÇALVES, Natália da Silva. Comentários ao caso m/v "Virginia" (Panamá c. Guiné-Bissau), 14 de abril de 2014. In: MONEBHURRUN, Nitish. Decisões da corte internacional de justiça e do tribunal internacional sobre o direito do mar. $R D I$, Brasília, v. 12, n. 2, p. 55-63, 2014.

OSTROM, E. Governing the commons, the evolution of institutions for collective actions. Cambridge: Cambridge university Press, 1990.

PARANCE, Béatrice; VICTOR, Jacques de Saint. Repenser les comuns. Paris: CNRS éd., 2014.

PETERSMANN, Ernst-Ulrich. International Economic Law, "Public Reason" and Multilevel Governance of Interdependent Public Goods. Journal of International
Economic Law, n. 14, p. 23-76, 2011.

PNUD. Providing Global Public Goods: Managing Globalization. 25 Questions \& Answers. New York: UNDP/ ODS, 2002. p. 3-5. Disponível em: <http://web.undp. org/globalpublicgoods/globalization/pdfs/ques-ans. pdf > . Acesso em: 10 maio 2015.

REID, Keith. Conserving Antarctica from the Bottom Up: Implementing UN General Assembly Resolution 61/105 in the Commission for the Conservation of Antarctic Marine Living Resources (CCAMLR). Ocean Y.B., n. 25 (131), 2011.

ROSSI, Christopher R. A particular kind of the grotian tendency and the global commons in a time of high arctic change. In: Int'l L \& Int'l Rel, n. 11 (1), 2015.

SALMON, J. (Dir.). Dictionnaire de droit international public. Bruxelles: Bruylant, 2001.

SCHEMEIL, Y. Des types purs de ressources mondiales communes non marchandes? AFSP / Section d'Etudes Internationales - Colloque Les biens publics mondiaux. Pau, 2001.

SHACKELFORD, Scott J. The Tragedy of the Common Heritage of Mankind. Stan Envtl LJ, n. 28, 2009.

SHAFFER, Gregory. International Law and Global Public Goods in a Legal Pluralist World. The European Journal of International Law, v. 23, n. 3, p. 669-693, 2012.

STAIGER, R.W. Report on the International Trade Regime for the International Task Force on Global Public Goods. 2006. Disponível em: <http://www.regeringen.se/contentasset s/4e7cc9afcd2444d38d5b507bb6cf9b49/global-publicgoods-international-trade>. Acesso em: 10 jun. 2015.

TELESETSKY, Anastasia. Laundering Fish in the Global Undercurrents: Illegal, Unreported, and Unregulated Fishing and Transnational Organized Crime. Ecology L.Q., n. 41, p. 939-998, 2014.

THEYS, J.; FAUCHEUX, S.; NOËL, J.F. La guerre de l'ozone. Futuribles, n. 125, p. 51-66, out. 1988.

TRÉBULLE, F. G. La propriété à l'épreuve du patrimoine commun: le renouveau du domaine universel. Études offertes an professeur Malinvand, Lexis Nexis. 2007. 
Para publicar na Revista de Direito Internacional, acesse o endereço eletrônico www.rdi.uniceub.br ou www.brazilianjournal.org.

Observe as normas de publicação, para facilitar e agilizar o trabalho de edição. 